\title{
OPTIONS, UNCERTAINTY AND CAPABILITY DEVELOPMENT
}

\author{
KREMLJAK, Z. \& KAFOL, C.
}

Abstract: Real options theory has proved to be a leading heuristics for dealing with uncertainty related events. Within the aforementioned scientific areas, the need of dealing with uncertainty is reflected in the development \& research projects, the development of new production technologies, development of new products projects, investments in advance manufacturing technology, the decisions for outsourcing production and development of production skills as flexibility in the production, logistics and quality control and maintenance. The globalization of the world today made the technology universal, without any barriers to the transfer and use. The single obstacle is posed by market and capital interests. All these changes are accompanied with an adequate search for new approaches in the organization models and production management. A long-term planning is impossible in environment of uncertainty and continuous changes. The uncertain global environment leaves time and risk as an opportunity. Decision making in such uncertain conditions is one of the hugest challenges that require proper understanding of complex processes.

Key words: risk, uncertainty, capability development, real option, investment, flexibility
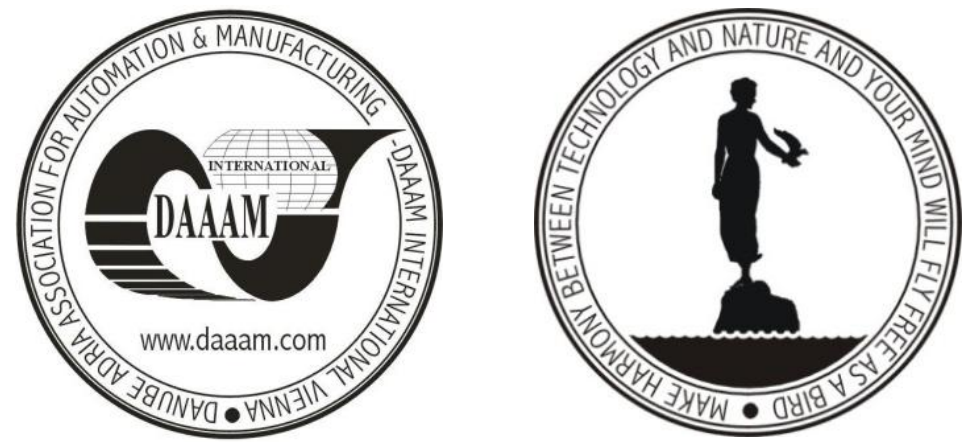

Authors' data: Assistant Prof. Dr. Sc. Kremljak, Z[vonko]; M. Sc. Kafol, C[iril], Telekom Slovenije, d. d. Cigaletova 15, SI - 1000 Ljubljana, Slovenia, EU, zvonko.kremljak@s5.net; cirilkafol@volja.net

This Publication has to be referred as: Kremljak, Z[vonko] \& Kafol, C[iril] (2012). Options, Uncertainty and Capability Development, Chapter 07 in DAAAM International Scientific Book 2012, pp. 075-086, B. Katalinic (Ed.), Published by DAAAM International, ISBN 978-3-901509-86-5, ISSN 1726-9687, Vienna, Austria DOI: $10.2507 /$ daaam.scibook.2012.07 
Kremljak, Z. \& Kafol, C.: Options, Uncertainty and Capability Development

\section{Introduction}

The globalization of the world today made the technology universal, without any barriers to the transfer and use. The single obstacle is posed by market and capital interests. All these changes are accompanied with an adequate search for new approaches in the organization models and manufacturing management. A long-term planning is impossible in environment of uncertainty and continuous changes. The uncertain global environment leaves time and risk as an opportunity. Decision making in such uncertain conditions is one of the hugest challenges that require proper understanding of complex processes (Trigeorgis et al., 2010).

In the engineering field, we have witnessed an intensive development of methods, tools and techniques which, according to their origin, fall under the area of applied mathematics, computer science, research activities and theory of economics (genetic algorithms, evolutionary programming, genetic programming, fuzzy logic, neural networks, real options theory, and etc.) used very successfully to solve various technical optimization problems. Real options theory is equally used in processing technologies, development and research, as well as in the production.

Real options theory has proved to be a leading heuristics for dealing with uncertainty related events. Within the aforementioned scientific areas, the need of dealing with uncertainty is reflected in the development $\&$ research projects, the development of new production technologies, projects for development of new products, investments in advance manufacturing technology, the decisions for outsourcing production and development of production skills as flexibility in the production, logistics and quality control and maintenance. The managers of the industrial enterprises, public institutions and service-providing companies face high level of uncertainty in the decision-making process, due to rapid and huge changes that determine the environments in which their organizations operate. Decisionmaking under high uncertainty becomes one of the most studied phenomena in the fields of strategic management, organisation theory, industrial management and development and research management (Nembhard \& Aktan, 2009).

\section{Problem formulation}

Managers of the industrial enterprises, public institutions and service-providing companies face high level of uncertainty in the decision-making, due to rapid and huge changes that determine the circumstances in which their organizations operate. Decision-making under high uncertainty has become one of the most studied phenomena in the fields of strategic management, organisation theory, industrial management and development and research management (Carpenter \& Fredrickson, 2001).

Uncertainty is a phenomenon that resists measurability; hence it's impossible to effectively limit the associated probabilities. Unlike the uncertainty, the risk can be measured along with levels of probability and can be managed. There is a definition of the uncertainty, according to which we never have a complete description of the world or the situation that we believe it is true. The definition implies that the 
probability of an event occurring as a result of certain activities cannot be determined objectively, but it is rather just a result of subjective assumptions. The failure to adjust to uncertainty additionally increases cognitive limitations of people. The cognitive basis of people consists of assumptions about the future and awareness of the possible alternatives and knowledge that enable one to realize the consequences that stem from the decision-making. This cognitive basis is highly limited and describes the occurrence/phenomenon of the limited rationality. It means that managers do not have complete information about the upcoming events when deciding, they do not know of all possible alternatives and are not aware of all possible decisions (Kremljak, 2004).

Dealing with uncertainty implies development of heuristic tools which can offer some sufficient solutions, but in the same time, not optimal ones. Simulation methods based on extrapolation of measurable data from the past are not proper for assistance in the decision-making under uncertainty. These are replaced by quality methods, as the scenario method, and the Delphi method. However, these methods are same inapplicable due to various reasons in the majority of decision-making cases, determined by high level of uncertainty. Recently, the real options theory appeared as dominant heuristics (rule of thumb) for problem solving in the decision-making under high level of uncertainty. This theory stems from the financial options theory, developed by the Nobel Prize winners Black and Scholes (1973). They developed a stochastic differential equation that enables valuation of the financial opportunities under uncertainty. The financial options logic spread quickly to the real options logic dealt with by a substantial part of the scientific literature. The financial option is an option to buy or sell a financial asset that already exists and which it is sold on the financial markets in the form of shares or bonds. Unlike the financial option, the real option is an option for change of the real assets, resources and intellectual activities, such as the following: establishment of new factory, conquering new markets, development of new technologies and products. Therefore, real options approaches are currently used for investments valuation in the areas of research and development, in the development of new products in the manufacturing technology and the remaining manufacturing resources. The option is defined as a right, but not an obligation, to make that decision in the uncertain future, which is most favorable when the uncertainty will be disclosed in future. The real options theory gives an answer to the following question: What price is most suitable for buying or selling, and what is the most suitable time to use the option.

The opinions regarding the applicability of the real options theory have also spread over to the strategic management area. Various authors claim that the real option theory is real heuristics for the management of the capability development process. The capability is defined as the organization knowledge of the company which enables the operation of the business processes. The strategic schools for dynamic capabilities claim that, due to their characteristics such as the systemic complexity and the historical dependency, capabilities serve as foundations to achieve long-lasting competitive advantages. The same characteristics that make capabilities difficult to copy and difficult to transfer and therefore, strategically valuable, actually limit the possibilities of successful management of the capabilities 
development process. This is distinguished by a high level of uncertainty, and therefore the real options theory appears as heuristics, having enough potential to assist managers in the management of the capabilities development process.

The different types of uncertainty are elaborated below. The real options theory as well as the areas, where this theory can serve as efficient heuristics, are hereby presented. Presented here are more details concerning its adequacy to the management of capability development, as well as the resources that limit its applicability (Adner \& Levinthal, 2004).

\subsection{Types of uncertainties}

Parametrical uncertainty is a kind of uncertainty that can be controlled mathematically. $U(a ; c ; \pi)$ is a function comprising action $(a)$ and expected consequences $(c) .\{a\}$ is a set of possible actions that can be derived $a=(1, \ldots, A)$, while $\{s\}$ is a set of possible situations, $s=(1, \ldots, S)$ and $\left\{c_{a s}\right\}$ set of consequences that stem from the interaction between actions and situations. $\{\pi\}$ is set of subjective probabilities related to the consequences and the situations.

The parametrical uncertainty can now be defined accurately. It means that the one deciding from a full range of activities which can be realized is aware both of all possible situations and all possible consequences stemming from those actions. It implies absolutely complete awareness in terms of the structure of the decisionmaking problem $\{a\},\{s\},\left\{c_{a s}\right\}$. The uncertainty refers to the subjective probability parameters $\{\pi\}$.

The structural uncertainty means that the person making the decision does not have a complete knowledge of the problem's structure. In other words, the person does not have a complete knowledge of the three parameters $\{a\},\{s\},\left\{c_{a s}\right\}$. Research projects provide no awareness of all possible consequences. Both the structural and the parametrical uncertainties depend on the external uncertainty.

The uncertainty is even greater if one takes into consideration the limited rationality. Such uncertainty is called radical uncertainty. It does not depend only on incomplete information, but also on the cognitive limitations of the person that makes the decision. The cognitive limitations are not just a consequence of people's incapability to process great number of actions, alternatives and consequences, but it also refers to the subjective capabilities related to the retrospective perception and interpretation, as well as the presentation based on the experience.

\subsection{Real options theory and applicability}

The evaluation of the options based on the work done by Einstein (1956) and Wiener (1923) in the field of diffusion in fluids obtains its final form in the equation of Black and Scholes:

$$
r V=r\left(\frac{\partial V}{\partial S}\right) S+\frac{\partial V}{\partial t}+0,5 S^{2} \sigma^{2}\left(\frac{\partial^{2} V}{\partial S^{2}}\right)
$$

Therein, $V$ is the function of motion quantities which can be viewed at any given time. $V$ is dependent on two values, $V(S, t) . S$, be the price of the instrument which varies constantly in time $t . R$ is the interest rate in the equation, while the $\sigma$ is the 
volatility of the instrument's value.

To understand the real option logic, it is important to understand that the instrument's $S$ evolution of values possesses the Wiener process characteristics and can be presented with the following equation:

$$
d S=m S \cdot d t+\sigma S d X
$$

The Wiener process is a combination of a deterministic trend that illustrates $m S d t$ and describes the growth and reduction in the $S$ value. $\sigma S d X$ is a random component having the characteristics of the Brownian motion. It is a characteristic of a random walk. The expression (2) means that the evolution of values is combination of both deterministic and stochastic motions. The Brownian motion is important because it gives the motion with characteristics of the Markov process. In other words, in order to predict the future $S$ values, the most important is the present value $S$, rather than the past motion trend $S$.

The real options logic can be presented with an analysis of the variables that influence over the value of the option. In order to illustrate the real option logic, the following simple example is taken: The value of the option $O_{v}$ is presented with the function:

$$
O_{v}=\mathrm{f}(S, \sigma, E, T, r)
$$

An example of the real options logic can be presented by the industrial company that decides whether is suitable or not to invest in technology development. Successfully developed technology will in future enable the development and sales of the products. Through the investments in technology development, the company creates a possibility for development and products commercialization. Put simply, the net present value of the project depends solely on the quantity of the product that will be sold in future. It is impossible to predict the changes of these quantities and that represents uncertainty in the investments-related decisions. Suppose that the investments in technology development are in the amount of 0.1 million $€$. That means that the price is such that there is opportunity to develop and sell the product even in future. Let's assume that it is necessary to invest 1 million $€$ (products development costs, technology investments and sales) in order to penetrate the market. In the event that at certain point of time on the project the $N P V$ of the projected amount of 0.75 million $€$, is affordable for us to invest in the development of the technology, but yet to wait with the investment in the development of products, manufacturing and market. The investment in the development of these will take place if $N P V$ in future exceeds the value of 1 million $€$ (Table 1 ).

The value of the option is increased by the variables $S, \sigma, T, r$. If $\sigma$ is zero, the option will have no value, because one can certainty tell what would $S$ be. In other words, the option is only valuable if one is talking about decision-making under uncertainty. The higher the $T$ the more time is there to defer the decision-making, which in turn increases the value of the fact that we have an option. $E$ variable decreases the value of the option.

The real options method is widespread in the evaluation of investment projects. It has been used to deal with research and development projects, technology 
investment projects, module developments and investments in manufacturing sources. The real options model uses analytical calculation of differential equations, finite elements method and simulation of decision trees.

\begin{tabular}{|c|c|c|}
\hline Variable & Description & Example \\
\hline$S$ & $\begin{array}{l}\text { Net present value of } \\
\text { the potential project if } \\
\text { the investment is } \\
\text { implemented today. }\end{array}$ & $\begin{array}{l}\text { Net present value of the project depends on the } \\
\text { quantities of the product sold. It is constantly } \\
\text { changing. }\end{array}$ \\
\hline$E$ & Strike price. & $\begin{array}{l}\text { Investment in the value of } 1 \text { million } € \text { is the fixed } \\
\text { amount of the investment. }\end{array}$ \\
\hline$\sigma$ & $\begin{array}{l}\text { Uncertainty that } \\
\text { measures the } \\
\text { difficulty of assessing } \\
\text { the net present value } \\
\text { in future. }\end{array}$ & $\begin{array}{l}\text { The more uncertain the quantities motion, the } \\
\text { bigger possibility for a positive income. A } \\
\text { negative income is only related to the investment } \\
\text { in technology development in the amount of } 0.1 \\
\text { million } € \text {. }\end{array}$ \\
\hline$T$ & Option maturity & $\begin{array}{l}\text { This is the difference between the date when the } \\
\text { option expires and the present date. In our case, } \\
\text { the option may expire if a rival appears on the } \\
\text { market, one that has already developed the } \\
\text { technology. In that case we could not defer the } \\
\text { decision concerning the investment } E \text {. }\end{array}$ \\
\hline$R$ & Interest rate. & \\
\hline
\end{tabular}

Tab. 1. Variables and characteristics of the real options

One should underline that the applicable models decrease the uncertainty of the parametrical uncertainty, whereupon it is possible to determine certain probability to each projection.

In addition to some simplifications concerning the uncertainty treatment, different authors suggest the real options theory as useful heuristics in the management of capability development process. The theory illustrates the basic strategic behaviour incorporated in the human intuition. It indicates that, in case of huge uncertainty, people have a tendency to have open options and to decide on one of them, when the uncertainty level decreases. The managers wait with the decisionmaking, meaning that these are irreversible investments until a business opportunity shows up. Before such an opportunity shows up, small investment is needed to secure the capabilities which will enable use of the investments. In the context of real options logic, the capabilities are presented as reserves of the company that enables the exploitation of future business opportunities (Trigeorgis, 2002).

The parallels between the real options theory and the capability development can be seen in the frameworks of the following features: uncertainty, compounded options, flexibility in the deferral of decision-making.

We limit our research to industrial investments under uncertainty using different strategic approaches, based on quantitative decision making. We are taking into account also the value of flexibility under uncertainty. 
The uncertainty in capabilities development is huge, because the managers do not know what business opportunities will show up in future, nor do they know what capabilities would be required to exploit these opportunities. This means that the uncertainty in the capabilities development is related to a double assumption.

Capabilities development is a specific case of compounded option. It is a type of option where the investment means that the company has received an opportunity to get future options. Investments in capabilities development cause capabilities accumulation process, and it is only after the knowledge is accumulated that the company gets the opportunity to respond to the business opportunities on the market (Kremljak \& Buchmeister, 2006).

The capabilities development is defined with high level of uncertainty due to the technological and market uncertainties. The real options logic underlines the importance of the decisions-making deferral which would translate into big and irreversible investments (Kogut \& Kulatilaka, 2001).

In spite of the obvious similarities between the capabilities development and the real option theory, the development of the heuristics for applied use which is supposed to offer measurable indicators to the managers, as support in the decisionmaking is restricted by some problems. The uncertainty described by Loasby (1998) is radical uncertainty. The managers are not able to set measurable objectives for the future, from a simple reason, because they do not know what business opportunities will show up. The timeframe of capabilities development is quite unclear, and the uncertainty is not constant and varies a lot (McGrath et al., 2004).

\section{Example}

Investment under uncertainty - the rule of the present value $N P V$ :

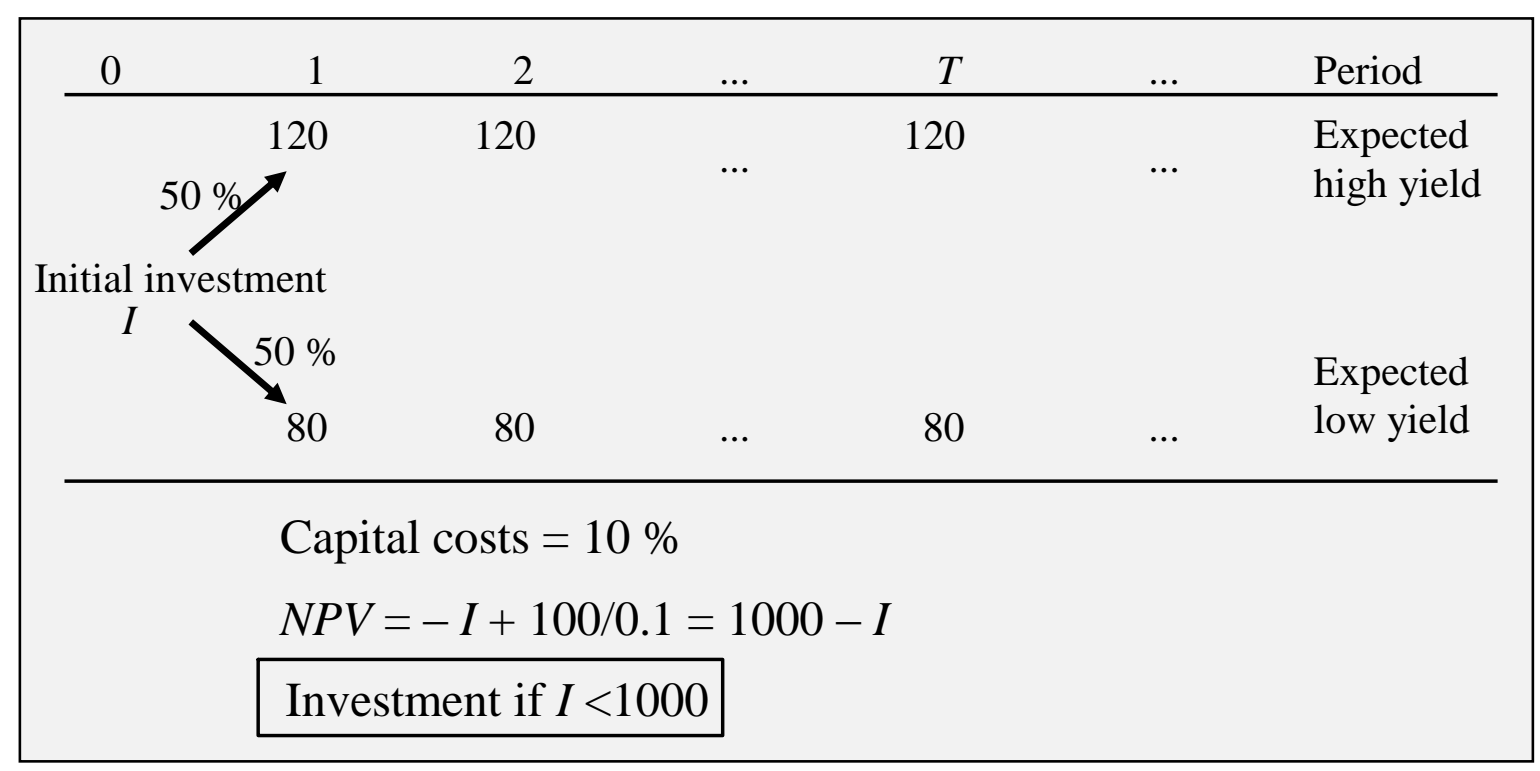

Investment under uncertainty - waiting

(Strategy: Waiting in the period)

Example 1: $I>800$, we do not invest - low yield 


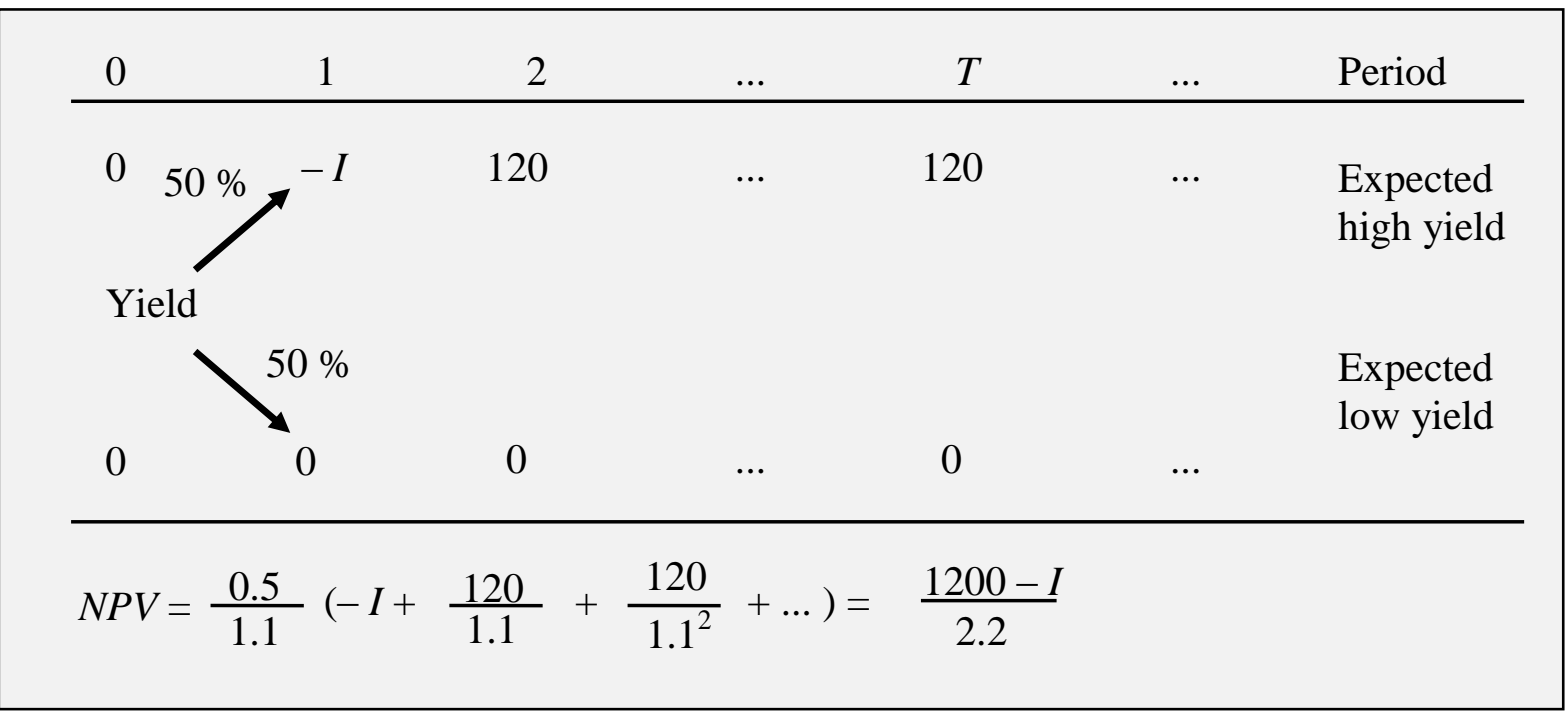

Investment under uncertainty - waiting 2

(Strategy: Waiting for a certain period)

Example 2: $I<800$, continuous investment

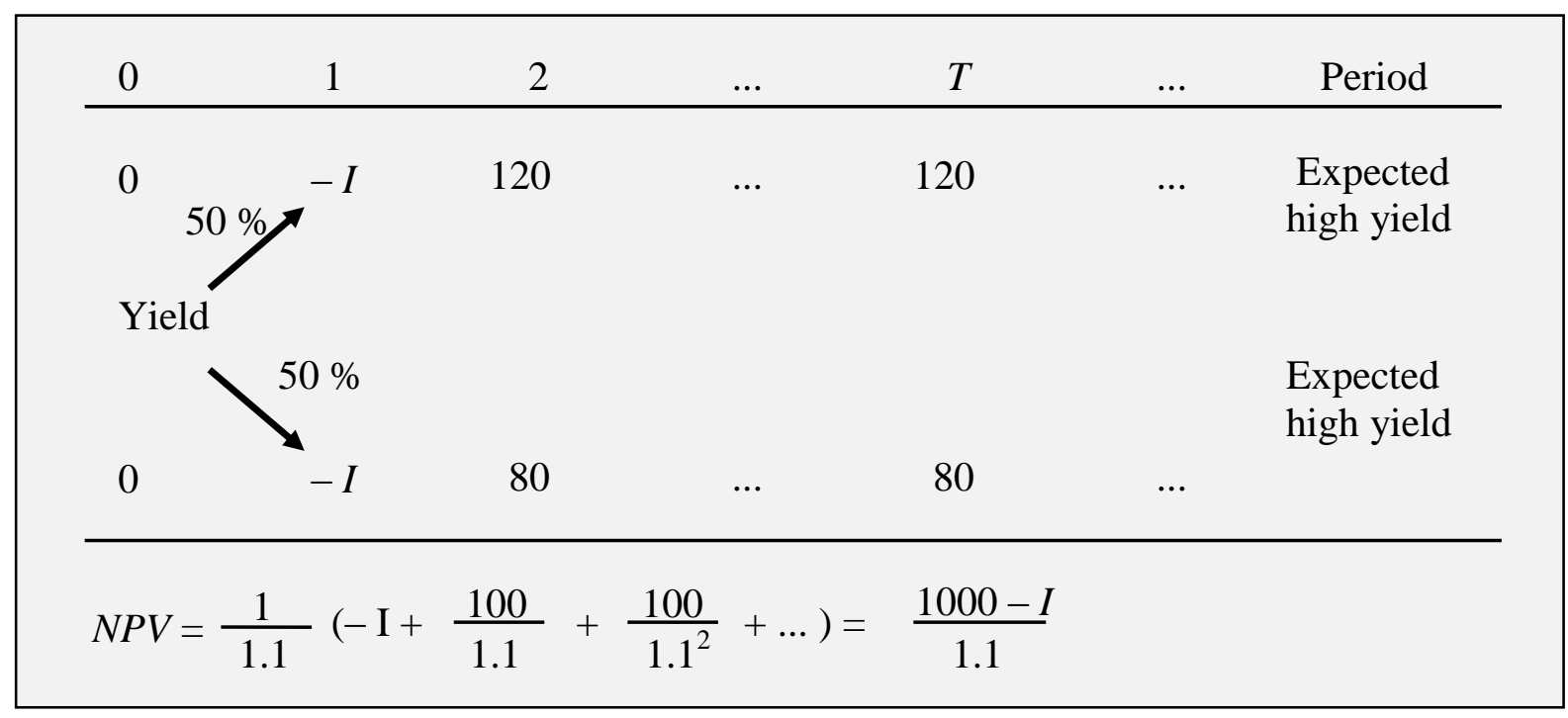

Summary of the strategies:

\begin{tabular}{c|l|c} 
No. & Rules of decision-making & $N P V$ \\
\hline$(1)$ & Currently $N P V$ & $1000-I$ \\
$(2)$ & Delay if $I>800$ & $(1200-I) / 2.2$ \\
$(3)$ & Delay if $I<800$ & $(1000-I) / 1.1$
\end{tabular}

The delay is never optimal if the $I<800$.

Better later than investing now the $I>833$.

The investment is not optimal if the $I>1200$. 
3.1 Comparison between the two strategies

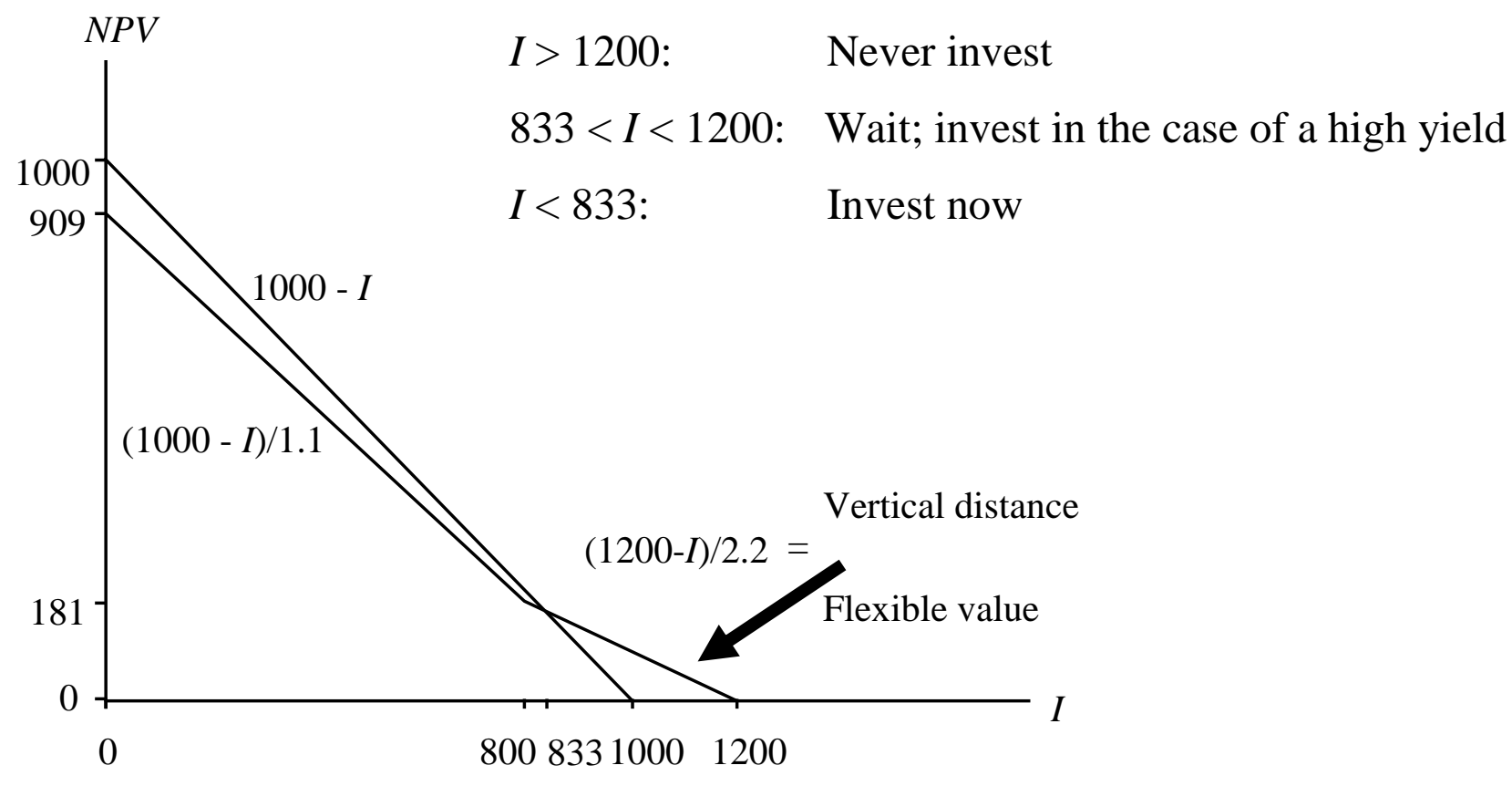

Comparison of results (1):

If $833<I<1000$ :

The investment has currently positive $N P V=1000-I$.

However: waiting is the best choice; let's see what would happen with the uncertainty regarding the demand.

- Benefits of waiting: gathering information to avoid losses.

- Costs due to the waiting: delay in receiving the cash flow. The investments in projects with positive NPV are not always optimal:

- The flexibility you gain by waiting for a positive value

Note: The critical point is 833 and not 800 .

\section{Comparison of results (2):}

If $1000<I<1200$ :

The investment now has negative $N P V$.

In any case: The project needs to be stopped, if the yield later goes up, there is a positive $N P V$.

Negative $N P V$ - the project needs to be put on hold, but not necessarily to be stopped.

The project can be stopped in two directions:

- Total $N P V$ and simple $N P V$ - including the value of flexibility

The investment has:

- The simple $N P V$ is $1000-I$.

The investment flexibility includes option of waiting.

The value of flexibility is:

$=$ Max (Value of the investment later - Value of the investment now, 0 of the whole project 
Simple $N P V+$ value of flexibility:

- Immediate investment ignores the option of waiting.

- The decision needs to be made on the basis of the total NPV.

The value of flexibility is never negative.

The total $N P V$ always leads to the right decisions.

Value of flexibility, how to use it - total $N P V$ :

If $I<833$, the investment should be now, the waiting option has no value.

If $1000>I>833$, then:

- The value of the investment now $=1000-I$

- The expected value of the investment later: $(1200-I) / 2.2$

- $(1200-I) / 2.2-(1000-I)=(1.2 I-1000) / 2.2$

Hence, having $I=833$, the value of flexibility 0 , with $I=1000$ this is increased to 91 .

If $1200>I>1000$, the value of the flexibility is simply: $(1200-I) / 2.2$.

Assumption: $I=900>833$, so the value of flexibility is positive.

- The value that results from adhering to the optimal strategy $=$ Total NPV

- The value of the investment now $=$ simple $N P V$

- Value of flexibility $=80 / 2.2=36.4$

The investment now is: $1000-900=100$,

- Simple $N P V=100>0$

Investment later is:

- Total $N P V=$ Simple $N P V+$ Value of flexibility $=100+36.4=136.4$

Total $N P V>$ simple $N P V$, thus, it's better to wait!

- The decision-making based on the simple $N P V$ ignores the current investment "kills the option";

- The basis for decision-making is always the total NPV.

\subsection{Influence over uncertainty}

Value of flexibility under uncertainty - we should compare the previously mentioned example with a condition of more volatile prices:

- Income $($ High demand $)=150$.

- Income $($ Low demand $)=50$.

The expected income is unaltered $(=100)$.

Volatility: the value of adjustability depends on uncertainty so that uncertainty is higher. 


\subsection{Flexibility under uncertainty}

Value of flexibility

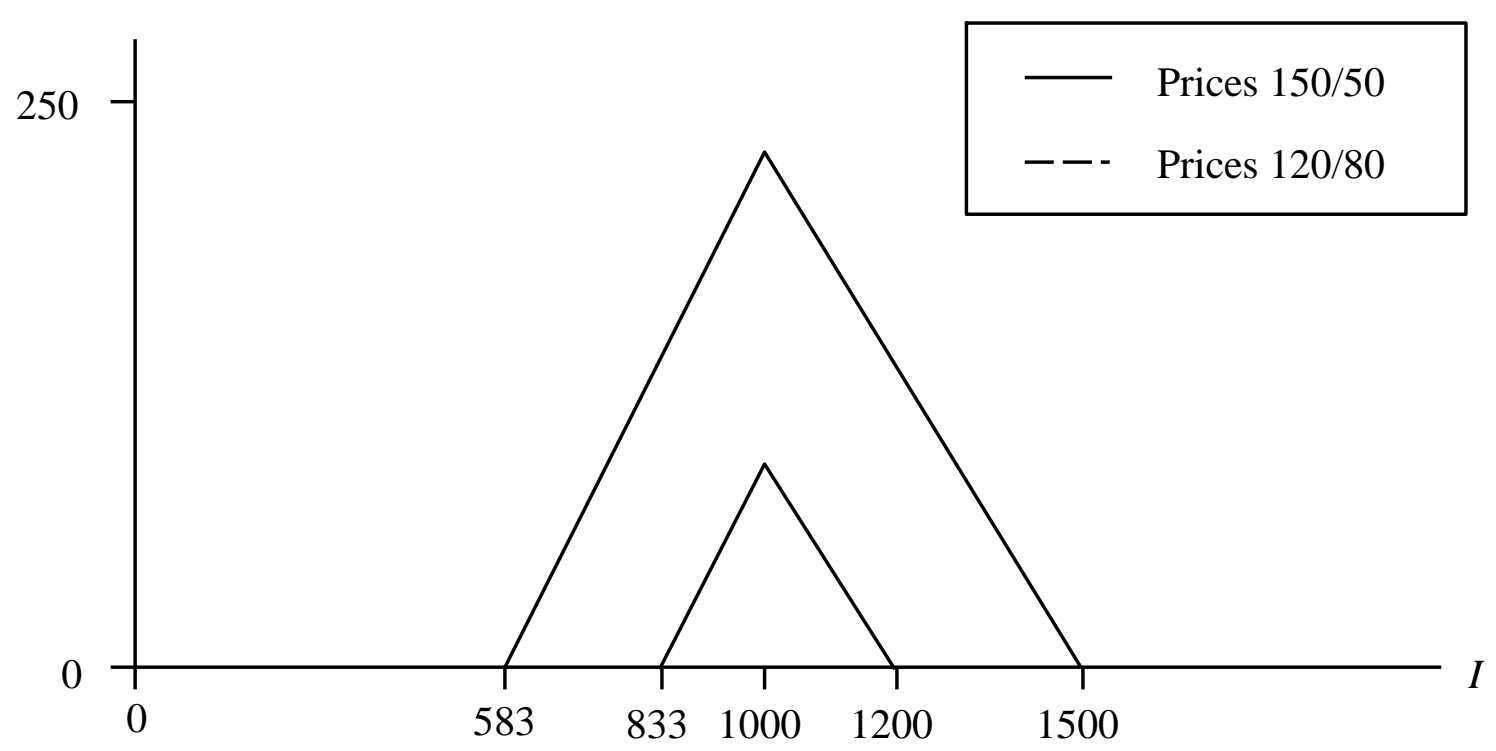

Flexibility has higher value under uncertainty.

\subsection{Option "giving up"}

Imagine the same scenario as the one presented before, but without the possibility for deferral:

Income $($ High demand $)=120$

Income $($ Low demand $)=80$

Investment expenditures $I=1010$

If there is no possibility for deferral $N P V=1000-I=-10$

- We do not invest!

If we assume the assets value following the writing-off:

- At the end of the period: value following the writing-off: 910

$\circ$ Following the first period: value following the writing-off: 0

Example of high income (120):

- $\quad P V($ cash flow $)=1200>910$

- We continue after the period 1 .

○ We receive: $1200+120$ in the period 1 .

Example of low income (80):

○ $\quad P V($ cash flow $)=800<910$

- Cancelation and giving up of the project in the period 1 .

○ We receive: $910+80$ in the period 1 .

$$
P V=\frac{910+80}{1.1} 0.5+\frac{1200+120}{1.1} 0.5=1050>1010
$$

With the possibility for giving up $N P V=40$.

Invest: Due to the possibility for giving up the project is acceptable. 
Kremljak, Z. \& Kafol, C.: Options, Uncertainty and Capability Development

\section{Conclusion}

The researches have so far shown that the capabilities development can be described with the logic of the real options theory and that the managers apply this logic intuitively in the structuring of the business decisions regarding capabilities development. There is lack of thorough studies to clarify the matter and the structuring of the business decisions in accordance with the recommendations of the real options theory. The conformity between the theory and the complex reality is not adequately explored yet and this is our next challenge for extensive future research. The same applies to the development of the applied methods which are adequate for guidance of the capabilities development. Such methods should provide measurable results, whereas the complex business realities should not be simplified to the extent of having useless results. The real options approach can help in two ways: it is future oriented and it can make the decision situation more understandable by giving relevant and quantified information relating to the management decisions.

\section{References}

Adner, R. \& Levinthal, D. A. (2004). What is not a real option: considering boundaries for the application of real options to business strategy. Academy of Management Review, Vol. 29, No. 1, 74-85

Black, F. \& Scholes, M. S. (1973). The pricing of options and corporate liabilities. Journal of Political Economy, Vol. 81, No. 3, 637-654

Carpenter, M. A. \& Fredrickson, J. W. (2001). Top management teams, global strategic posture, and the moderating role of uncertainty. Academy of Management Journal, Vol. 44, No. 1, 533-545

Einstein, A. (1956). Investigations on the Theory of Brownian Movement. Dover, New York

Kogut, B. \& Kulatilaka, N. (2001). Capabilities as real options. Organization Science, Vol. 12, No. 6, 744-758

Kremljak, Z. (2004). Decision making under risk, DAAAM International, Vienna

Kremljak, Z. \& Buchmeister, B. (2006). Uncertainty and development of capabilities, DAAAM International Publishing, Vienna

Loasby, B. J. (1998). The organisation of capabilities. Journal of Economic Behaviour \& Organization, Vol. 35, No. 2, 139-160

McGrath, R. G., Ferrier, W. J. \& Mendelow, A. L. (2004). Real options as engines of choice and heterogenity. Academy of Management Review, Vol. 29, No. 1, 86101

Nembhard, H. B. \& Aktan, M. (2009). Real Options in Engineering Design, Operations, and Management, CRC Press, Boca Raton

Trigeorgis, L. (2002). Real options - Managerial flexibility and strategy in resource allocation, MIT Press, Cambridge

Trigeorgis, L., Brosch, R. \& Smit, H. (2010). Stay Loose, Dow Jones \& Company, New York

Wiener, N. (1923). Differential space. Journal of Mathematical Physics, Vol. 2, 131174 